14

\title{
Структура и физико-химические механизмы взаимодействия костной ткани с титановыми имплантатами в условиях туберкулезного остита
}

\author{
(c) О.Н. Мусская,, В.К. Крутько, ${ }^{1}$ А.А. Гайдаш, ${ }^{2}$ А.И. Кулак, ${ }^{1}$ Н.С. Чекан, ${ }^{2}$ К.В. Скроцкая, ${ }^{3}$ \\ М.С. Сердобинцев, ${ }^{2}$ А.А. Вишневский, ${ }^{2}$ Т.И. Виноградова, ${ }^{2}$ Е.К. Соколович, ${ }^{2}$ П.К. Яблонский ${ }^{2}$ \\ ${ }^{1}$ Институт общей и неорганической химии НАН Беларуси, \\ 220079 Минск, Беларусь \\ ${ }^{2}$ Санкт-Петербургский научно-исследовательский институт фтизиопульмонологии, \\ 191036 Санкт-Петербург, Россия \\ ${ }^{3}$ Научно-исследовательский институт фризико-химических проблем, \\ 220030 Минск, Беларусь \\ e-mail: musskaja@igic.bas-net.by
}

Поступило в Редакцию 30 июля 2018 г.

В окончательной редакции 23 октября 2018 г.

Принято к публикации 29 мая 2019 г.

Методами сканирующей электронной микроскопии, рентгенофазового анализа, ИК-спектроскопии и термического анализа исследованы структура и физико-химические механизмы взаимодействия костной ткани с титановыми имплантатами в условиях туберкулезного остита. Установлено, что физиологическая регенерация костной ткани на фоне лечения туберкулезного остита сопровождается ростом органической компоненты, охрупчиванием минеральной фазы костного матрикса и его мелкодисперсным распадом. Наличие титановых имплантатов в условиях физиологической нормы способствует активации синтеза апатитовой фазы в регенерирующей кости. Основным механизмом имплантационного остеогенеза при туберкулезном остите является образование неорганической фазы гидроксиапатита преимущественно в участках разрушения титанового сплава.

Ключевые слова: титановые имплантаты, гидроксиапатит, карбонатгидроксиапатит, костная ткань, туберкулезный остит.

DOI: $10.21883 / J T F .2019 .12 .48502 .304-18$

\section{Введение}

Возникновение костных дефектов в результате травм и протекания ряда заболеваний (остеопороз, остеоатрит, сахарный диабет, туберкулезный остит и др.) приводит к необходимости медикаментозного лечения либо полной замены поврежденной костной ткани $[1,2]$. Как правило, при восстановлении костных дефектов обычно используют биоинертные полимеры [3] и неорганические композиты [4,5], а при обширных повреждениях - металлические имплантаты [6,7]. Применение имплантатов на основе титана и его сплавов для замещения поврежденной костной ткани известно достаточно давно [7-9], что связано с их биоинертностью и прочностью. В настоящее время считается, что остеоинтеграция титановых имплантатов обусловлена оксидной пленкой титана, которая выступает как хемосорбент ионов $\mathrm{OH}^{-}$, повышающих гидрофильность его поверхности, благодаря чему обеспечивается высокая адгезия костной ткани к имплантату [8]. В некоторых случаях наблюдается реакция организма на имплантат, что обусловлено микропримесями (железо, хлор) в технически чистом титане либо легирующими добавками (ванадий, алюминий, цирконий и др.) в титановых сплавах [9]. Кроме того, в патологических условиях может запускаться каскад реакций, активно влияющих на регенерацию костной ткани. До сих пор особенности остеогенеза, протекающего в области контакта костной ткани и титановых имплантатов на фоне сопутствующих заболеваний, остаются малоизученными. В связи с этим целью настоящей работы являлось изучение структуры и физико-химических свойств регенерирующей костной ткани, контактирующей с титановыми имплантатами, в условиях туберкулезного остита на фоне лечения.

\section{1. Объекты и методы исследования}

Эксперименты проводили на половозрелых самцах кроликов породы Шиншилла на базе экспериментальной лаборатории Научно-исследовательского института фтизиопульмонологии (Санкт-Петербург). Протоколы экспериментов, включая содержание и способ эвтаназии, согласованы с этическим комитетом СанктПетербургского НИИ фтизиопульмонологии и соответствуют Правилам содержания лабораторных животных, утвержденным Приказом Министерства здравоохранения Российской Федерации. Животные были разделены на следующие группы (по 3 особи в каждой): 1) контрольная - здоровые кролики, 2) кролики со смоделированным туберкулезным оститом, 3) кролики с внедренными титановыми имплантатами, 4) кролики со смоделированным туберкулезным оститом и внедрен- 
ными титановыми имплантатами. Туберкулезный остит моделировали с помощью введения туберкулезных микобактерий в высверленные отверстия бедренных костей. Противотуберкулезная терапия во 2-й и 4-й группах была проведена по стандартной процедуре.

В качестве исследуемых материалов были использованы образцы эпифизов бедренных костей, вырезанных из области, контактирующей с поверхностью титановых имплантатов марки ВТ-6 (Ti-6Al-4V) в течение двух месяцев. Животных выводили из эксперимента с помощью летальных доз золетила.

Сканирующую электронную микроскопию (СЭМ) выполняли на микроскопе LEO 1420 (Германия) с энергодисперсионной приставкой для локального элементного анализа (EDAX). Сколы образцов для микроскопии получали в парах жидкого азота с последующей фиксацией в $2.5 \%$ глутаровом альдегиде, обезвоживанием в этаноле и напылением золота.

Рентгенофазовый анализ (РФА) образцов костной ткани, высушенных на воздухе до постоянной массы, проводили на дифрактометре ADVANCE D8 (Bruker, Германия) с использованием излучения $\mathrm{Cu} K_{\alpha}$ с длиной волны $1.5405 \AA$. ИК-спектры образцов регистрировали на спектрометре Tenzor-27 (Bruker, Германия) в диапазоне 400-4000 $\mathrm{cm}^{-1}$. Образцы для анализа готовили прессованием порошка растертой костной ткани в таблетки с бромидом калия. Относительную минерализацию коллагеновой матрицы (соотношение апатит/коллаген) оценивали по данным ИК-спектроскопии из соотношения площади характеристических полос (900-1200/1550-1800 $\left.\mathrm{cm}^{-1}\right)$, соответствующих колебаниям $\mathrm{PO}_{4}$ групп в составе гидроксиапатита (неорганическая фаза) и групп Амид I (органическая фаза), [10]. Термогравиметрию (ТГ), дифференциальную термогравиметрию (ДТГ) и дифференциальный термический анализ (ДТА) проводили на совмещенном термическом анализаторе Netzsch STA 409 PC Luxx (Германия); скорость нагрева $10.0^{\circ} \mathrm{C} / \mathrm{min}$ на воздухе, масса навески $40 \pm 10 \mathrm{mg}$.

\section{2. Результаты и их обсуждение}

\section{1. Регенерирующая костная ткань (1-я группа)}

По данным СЭМ в регенерирующей костной ткани наблюдаются очаги ремоделирования в виде скоплений остеобластов с характерными отростками на поверхности (рис. 1,a), а также костные пластинки, растущие в полости межклеточного пространства костного матрикса (рис. $1, b)$.

На рентгенограммах (рис. 2,a, дифрактограмма 1) образцов здоровой костной ткани видны уширенные дифракционные пики аморфизированного фосфата кальция с основными рефлексами в области $2 \theta 30-35^{\circ}$, характерными для гидроксиапатита, как нестехиометри- ческого состава (н-ГА), так и карбонатзамещенного (кГА) (табл. 1).

Согласно данным ИК-спектроскопии (рис. 2, $b$, кривая 1), в здоровой кости интенсивные полосы в области $3200-3600 \mathrm{~cm}^{-1}$ обусловлены валентными колебаниями ассоциированных О-Н- и N-H-групп в трехмерной структуре коллагена, а также наличием адсорбированной воды. Полосы при 2927 и $2856 \mathrm{~cm}^{-1}$ соответствуют колебаниям С-Н групп полипептидной цепи, а при $1745 \mathrm{~cm}^{-1}$ - колебаниям $\mathrm{C}=\mathrm{O}-$ и $\mathrm{N}-\mathrm{H}-г$ рупп аминокислотного остатка глицина в первичной структуре белка. Апатитовая фаза костной ткани проявляется при 455 и $565 \mathrm{~cm}^{-1}$ (плоскостные деформационные колебания $\mathrm{PO}_{4}$ групп), при 930-990 и 975-1140 cm $\mathrm{cm}^{-1}$ (валентные колебания $\mathrm{PO}_{4}$-групп). Свободная О-Н- группа н-ГА на ИК-спектре контрольного образца практически не видна, что свидетельствует об искажении кристаллической решетки гидроксиапатитовой фазы и его связывании с коллагеном за счет водородных связей. Кроме того, к искажениям кристаллической решетки гидроксиапатита приводят также изоморфные замещения О-Н (замещение Атипа) и $\mathrm{PO}_{4}$-групп (замещение Б-типа) на карбонатные группы. На ИК-спектре эти полосы видны при $1545 \mathrm{~cm}^{-1}$ (ассиметричные колебания связей С-O карбонатных групп А-типа к-ГА), 1465 и $1410 \mathrm{~cm}^{-1}$ (ассиметричные колебания связей С-О карбонатных групп Б-типа к-ГА), при $873 \mathrm{~cm}^{-1}$ (колебания связей О-С-О карбонатных групп Б-типа к-ГА). Следует отметить, что отнесение некоторых полос поглощения только к гидроксиапатитовой составляющей кости является условным, поскольку колебания связей С-О могут быть обусловлены также функциональными группами аминокислотных остатков коллагена. В связи с этим расчетные значения относительной минерализации коллагеновой матрицы носят оценочный характер и соотношение апатит/коллаген в контрольном образце составляет 48/52 (табл. 2).

Результаты РФА и ИК-спектроскопии подтверждаются данными термического анализа (рис. 3). Потеря массы образцов наблюдается в температурных интервалах при $50-200,200-400,400-550$ и $550-900^{\circ}$ С. Сначала происходит потеря структурной воды (9\%), на второй стадии удаляются низкомолекулярные органические вещества и неколлагеновые белки, а выше $400^{\circ} \mathrm{C}$ происходит разложение высокомолекулярных органических веществ и коллагена, что согласуется с литературными данными [11]. Принимая во внимание, что органическая фаза начинает удаляться только на второй стадии, ее содержание при пересчете на обезвоженные образцы составляет $49 \%$ (табл. 2).

\section{2. Регенерирующая костная ткань при туберкулезном остите на фоне лечения (2-я группа)}

В образцах костной ткани при леченом туберкулезном остите по данным СЭМ (рис.1, $c, d)$ выявлены морфологические признаки разбалансирования процессов 

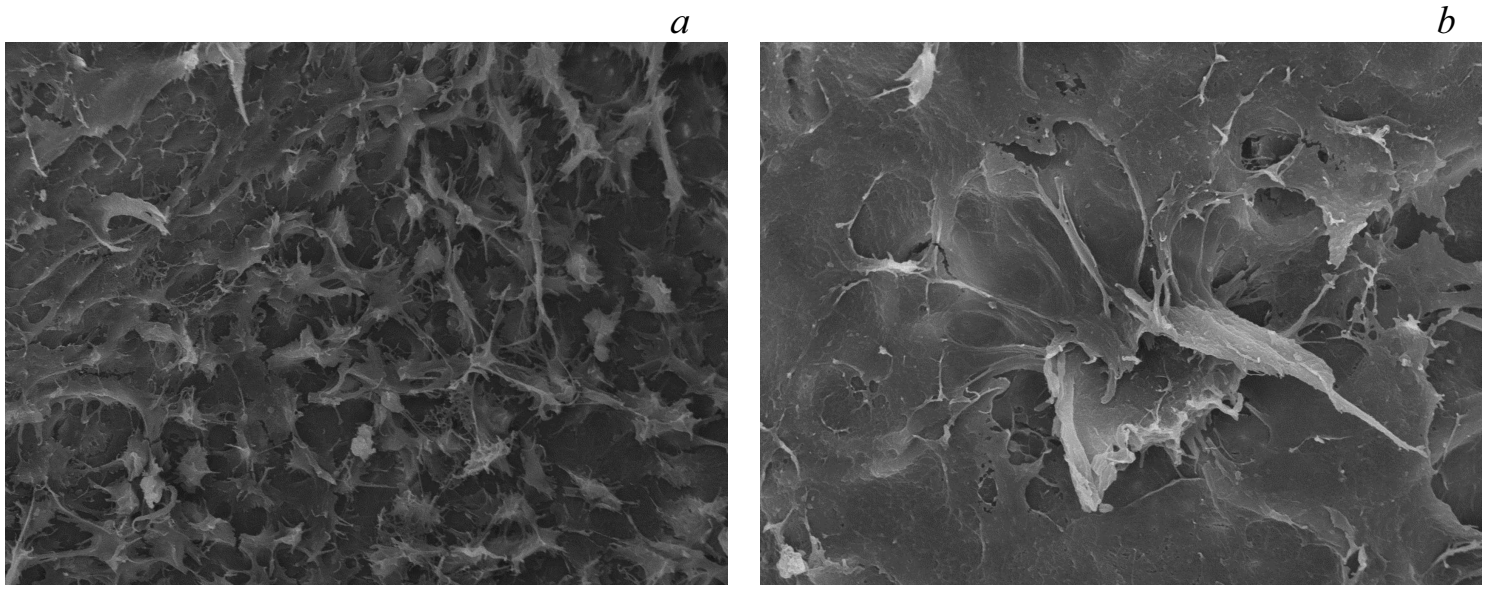
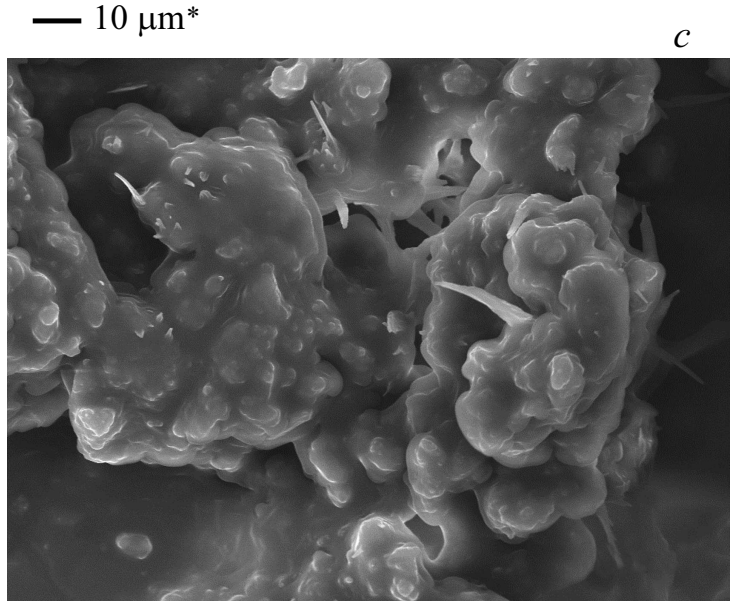

$10 \mu \mathrm{m}^{*}$

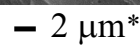

$d$

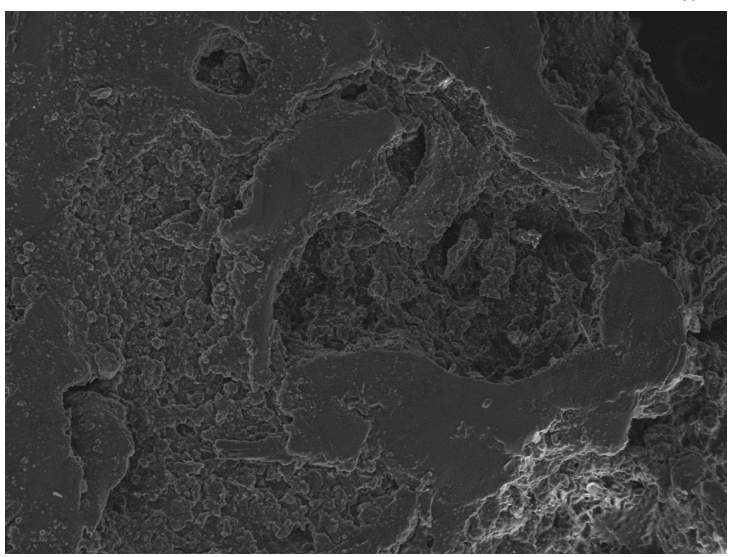

$200 \mu \mathrm{m}^{*}$

Рис. 1. СЭМ-изображения костной ткани, здоровой $(a, b)$ и на фоне лечения туберкулеза $(c, d): a-$ с очагами ремоделирования костного матрикса; $b-$ с новообразованными костными пластинками; $c-$ с матриксными пузырьками в цитоплазме и минеральноорганическими цитоплазматическими выростами; $d-$ с разрастанием костных трабекул.

Таблица 1. Фазовый состав и размер кристаллитов минеральной составляющей костной ткани (по данным РФА)

\begin{tabular}{c|l|c|c|c}
\hline \multirow{2}{*}{$\begin{array}{c}\text { No } \\
\text { группы }\end{array}$} & \multicolumn{1}{|c|}{ Образец } & Соотношение & \multicolumn{2}{|c}{ Размер кристаллитов, nm } \\
\cline { 3 - 5 } & Контрольный & н-ГА/к-ГА & н-ГА & 13 \\
\hline 1 & $\begin{array}{l}\text { Костная ткань после лечения } \\
\text { туберкулеза }\end{array}$ & $75 / 45$ & 10 & 12 \\
\hline 2 & $\begin{array}{l}\text { Регенерирующая костная ткань } \\
\text { с титановыми имплантатами }\end{array}$ & $61 / 39$ & 10 & 11 \\
\hline \multirow{2}{*}{4} & $\begin{array}{l}\text { Регенерирующая костная ткань } \\
\text { с титановыми имплантатами } \\
\text { после лечения туберкулеза }\end{array}$ & $61 / 39$ & 13 & 13
\end{tabular}

ремоделирования со смещением в сторону чрезмерного остеогенеза. Это проявляется в виде хаотичного разрастания костных трабекул, облитерации микропор и микрофитизации костного матрикса.

Методами РФА и ИК-спектроскопии установлено, что после лечения туберкулезного остита повышается коли- чество н-ГА (табл. 1) и уменьшается содержание апатитовой фазы (табл. 2). Причем тенденция в соотношении неорганической и органических фаз по данным двух видов анализа (ИК-спектроскопии и ДТА) совпадает.

Следует отметить, что на ИК-спектре (рис. 2, $b$, кривая 2) проявляются полосы, соответствующие колеба- 
Таблица 2. Расчетные данные относительной минерализации коллагеновой матрицы костной ткани

\begin{tabular}{c|l|c|c}
\hline \multirow{2}{*}{$\begin{array}{c}\text { № } \\
\text { группы }\end{array}$} & \multicolumn{1}{|c}{ Образец } & \multicolumn{2}{|c}{ Соотношение апатит/коллаген } \\
\cline { 3 - 4 } & Контрольный & Данные ИК & Данные ДТА \\
\hline 1 & $\begin{array}{l}\text { Костная ткань после лечения } \\
\text { туберкулеза }\end{array}$ & $48 / 52$ & $38 / 62$ \\
\hline 2 & $\begin{array}{l}\text { Регенерирующая костная ткань } \\
\text { с титановыми имплантатами }\end{array}$ & $51 / 49$ & $56 / 44$ \\
\hline \multirow{2}{*}{4} & $\begin{array}{l}\text { Регенерирующая костная ткань } \\
\text { с титановыми имплантатами } \\
\text { после лечения туберкулеза }\end{array}$ & $46 / 54$ & $45 / 55$ \\
\end{tabular}
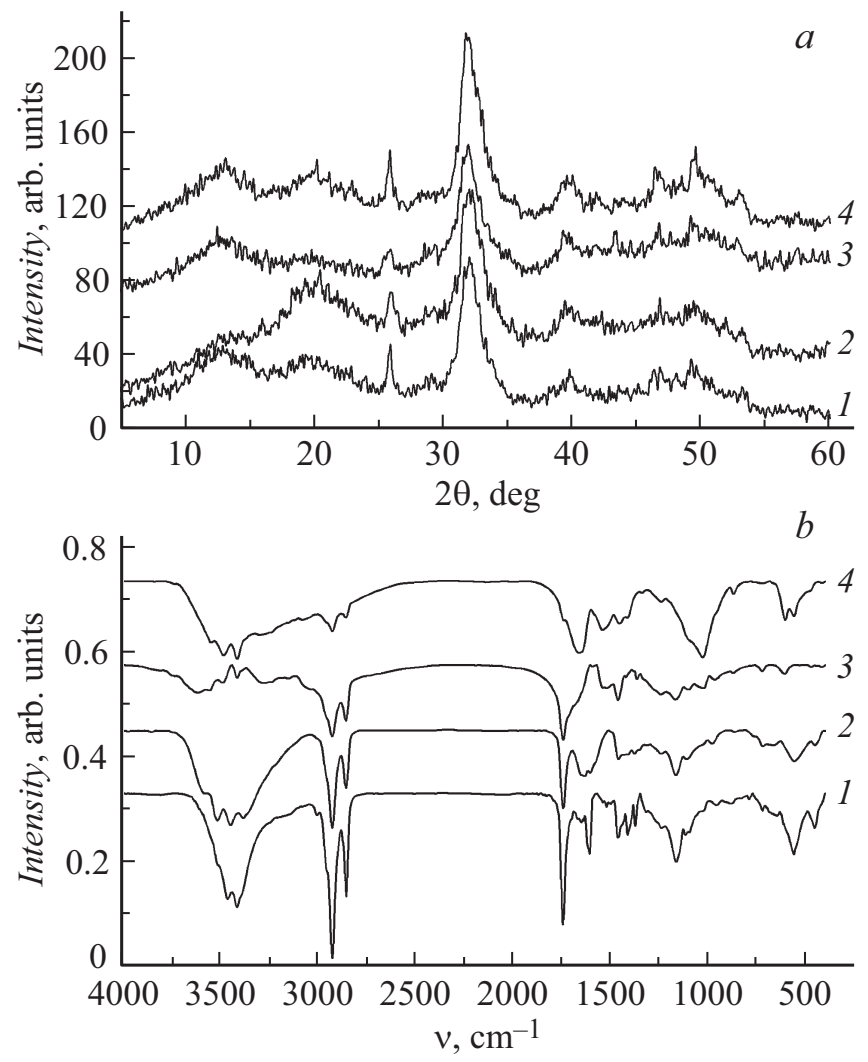

Рис. 2. Рентгенограммы $(a)$ и ИК-спектры $(b)$ образцов костной ткани, здоровой $(1,3)$ и на фоне лечения туберкулеза $(2,4)$ : 1,2 - физиологическая регенерация; 3,4 - регенерация с титановыми имплантатами.

ниям функциональных групп к-ГА смешанного АБ-типа. Присутствие карбонатных групп в кристаллической решетке гидроксиапатита способствует некоторому сближению атомов кальция и кислорода в составе гидроксильных групп, что приводит к формированию центров „известкования“. Появление подобных структурных сдвигов может изменять микромеханические свойства минеральной фазы костного матрикса и усиливать ее „вяжущие“ свойства.

\section{3. Регенерирующая костная ткань с внедренными титановыми имплантатами (3-я группа)}

При внедрении титановых имплантатов в костную ткань здоровых животных по данным СЭМ (рис. 4, $a$ ) в пограничной области выявляются характерные костные пластинки, свидетельствующие об активной регенерации. Важно, что структура титанового имплантата оста-
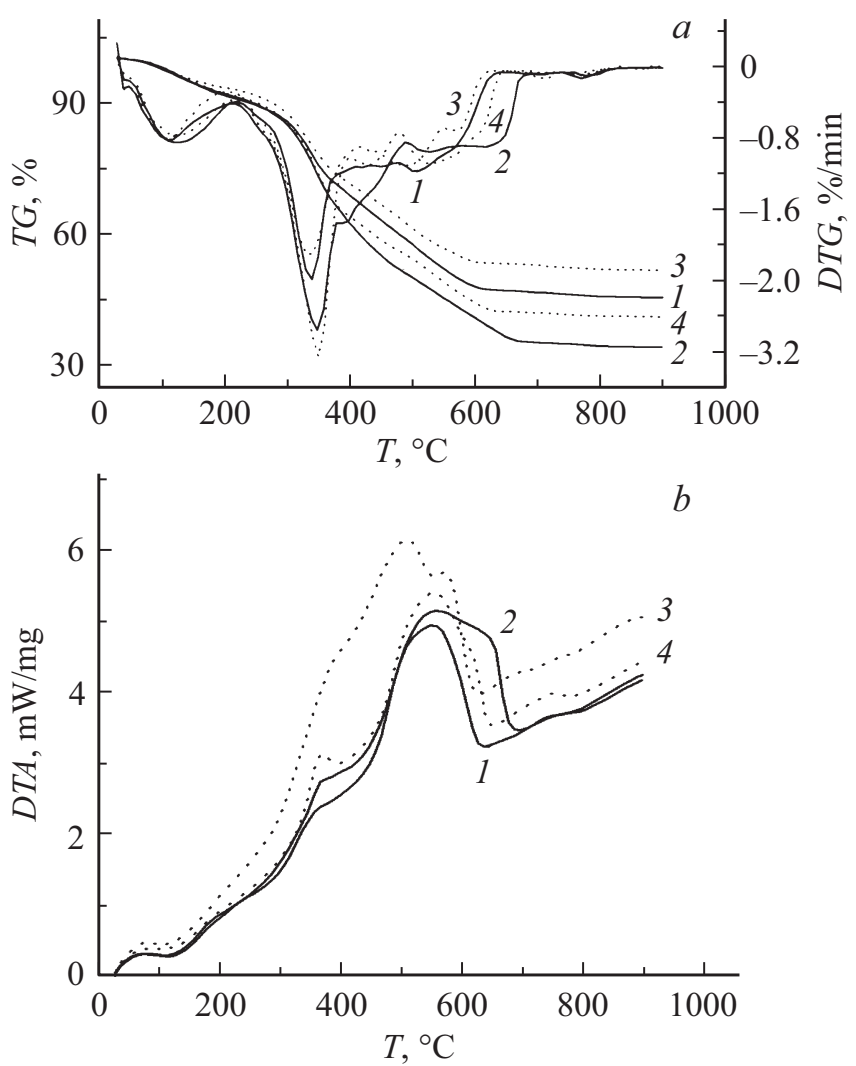

Рис. 3. ТГ, ДТГ $(a)$ и ДТА $(b)$ образцов здоровой $(1,3)$ и на фоне лечения туберкулеза $(2,4)$ костной ткани: $1,2-$ физиологическая регенерация; 3,4- регенерация с титановыми имплантатами. 


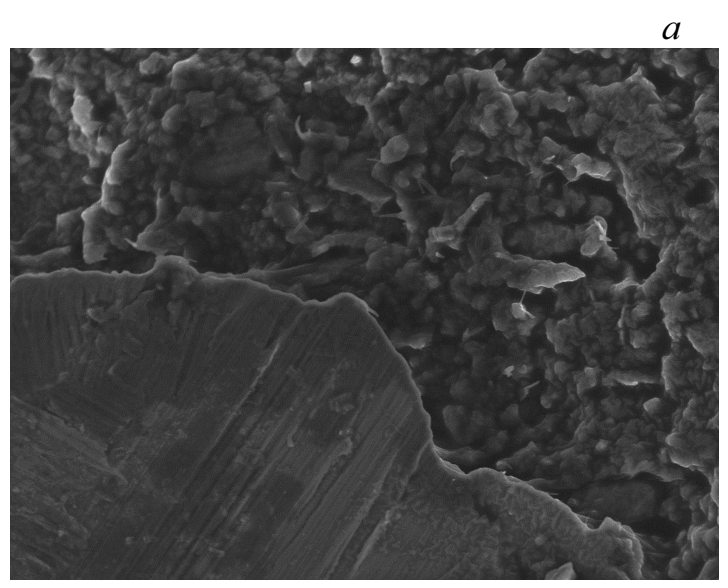

$20 \mu \mathrm{m}^{*}$

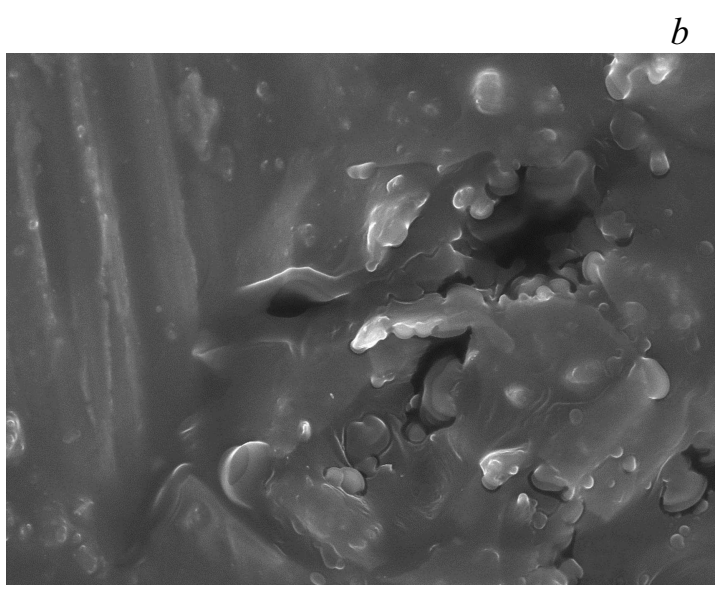

$-2 \mu \mathrm{m}^{*}$

Рис. 4. СЭМ-изображения пограничной области имплантата со здоровой костной тканью в зоне роста $(a)$ и структуры глубоких слоев спила титанового имплантата на фоне лечения туберкулезного остита $(b)$.

ется однородной, без щелей и трещин, что свидетельствует о ее сохранности в физиологических условиях.

По данным РФА (рис. 2, $a$, дифрактограмма 3) в образцах костной ткани, извлеченных из зоны имплантата, интенсивность основного рефлекса немного ниже по сравнению с образцами 1-й и 2-й групп и наблюдается тенденция к увеличению содержания н-ГА относительно к-ГА (табл. 1). Это указывает на стремление костной ткани к восстановлению апатитовой фазы в матриксе регенерирующей кости.

На ИК-спектре (рис. 2, $b$, кривая 3) уменьшается интенсивность полос в области валентных колебаний О-Ни N-Н-групп при $3600-3200 \mathrm{~cm}^{-1}$, отвечающих за водородную связь. Полосы, соответствующие карбонатным группам, наблюдаются только для Б-типа к-ГА. Кроме того, по сравнению с контрольным образцом снижается интенсивность полос, отвечающих колебаниям функциональных групп как органической составляющей, так и минеральной фазы костной ткани. Следовательно, при имплантации титановых матриц происходит повышение степени аморфности апатитовой составляющей костной ткани. По расчетным данным как ИК-спектроскопии, так и ДТА (табл. 2) содержание неорганической фазы повышается по сравнению с образцами предыдущих групп (без имплантатов). Это означает, что в сравнении с физиологической регенерацией титановые имплантаты оказывают стимулирующее воздействие на процессы репаративной регенерации.

По данным ДТА (рис. 3) видно, что для всех образцов костной ткани дегидратация происходит до $200^{\circ} \mathrm{C}$ практически с одинаковыми скоростями. Обращает на себя внимание, что, начиная с $350^{\circ} \mathrm{C}$, скорость распада коллагеновых белков в разных группах отличается. В частности, при регенерации костной ткани на фоне туберкулеза в образцах регистрируется более интенсивный распад органической фазы по сравнению с контрольной группой. Существенные различия наблюдаются для образцов в диапазоне $600-900^{\circ} \mathrm{C}$ : при имплантационном остеогенезе по сравнению с контрольным образцом остается большее количество неорганической фазы в сухом остатке, т.е. в этих условиях образование неорганической фазы происходит быстрее, чем в контрольном образце.

\section{4. Регенерирующая костная ткань с внедренными титановыми имплантатами на фоне лечения туберкулезного остита (4-я группа)}

По данным СЭМ (рис. 4, b) основными особенностями в этой группе образцов являются множественные эрозии и литические каналы с фестончатыми краями дефектов в глубинных слоях титановых имплантатов. Принципиально важно, что новообразованная костная ткань прорастает вглубь коррозированного имплантата. При этом наблюдается миграция мелких клетокпредшественников остеогенной направленности в щели диаметром до 5-10 $\mu \mathrm{m}$. В участках большего объема клетки дифференцируются в зрелые остеобласты с костными пластинками эмбрионального типа. В целом структура контактной области с имплантатом неоднородна, что создает условия для значительного варьирования кислотно-основного равновесия тканевой жидкости. В частности, области со щелочной средой будут способствовать коррозии титана, о чем свидетельствует преимущественное осаждение гидроксиапатита в зонах коррозии.

Согласно данным РФА, в регенерирующей костной ткани с внедренными титановыми имплантатами при туберкулезном остите по сравнению с физиологической регенерацией (3-я группа) происходит некоторое повышение степени кристалличности неорганической фазы и размера кристаллитов н-ГА и к-ГА (рис. 2, $a$, дифрактограмма 4, табл. 1). На ИК-спектре (рис. 3, кривая 4) наблюдается смещение сильной амидной полосы I, соответствующей карбонильному поглощению 
при $1745 \mathrm{~cm}^{-1}$, и полосы валентных колебаний С-О при $1165 \mathrm{~cm}^{-1}$ по сравнению с аналогичными образцами здоровой костной ткани. Отсутствие пика при $1540 \mathrm{~cm}^{-1}$, согласно [10], указывает на преобладание Б-типа к-ГА в данных образцах. Повышение содержания неорганической фазы (табл. 2) в образцах регенерирующей костной ткани с внедренными титановыми имплантатами после лечения туберкулезного остита свидетельствует о менее интенсивном росте соединительной коллагеновой ткани по сравнению с костной тканью без имплантата в этих условиях. Кроме того, образцы костной ткани 4-й группы характеризуются более высокой термостойкостью, связанной с плотной упаковкой коллагеновых волокон, что затрудняет удаление летучих продуктов распада органических соединений из образцов [12]. На кривых ДТА это проявляется в смещении тепловых эффектов в область высоких температур на 3-й и 4-й стадиях. Обращает на себя внимание, что при регенерирующем туберкулезном остите уменьшение неорганической фазы наблюдается в большей степени, чем при имплантационном остеогенезе при туберкулезном остите, т. е. титан в условиях туберкулеза в большей мере по сравнению с физиологической нормой способствует образованию фазы гидроксиапатита.

\section{Заключение}

Регенерация костной ткани в физиологических условиях и при туберкулезном остите реализуется на фоне различных структурно-фазовых преобразований неорганической и органической фаз. Регенерация костной ткани на фоне лечения туберкулезного остита характеризуется уменьшением содержания апатитовой фазы с преобладанием н-ГА (до 77\%), стремящегося к стабильной стехиометрической форме. При этом костный матрикс разрушается по хрупкому механизму с мелкодисперсным распадом.

Имплантационный остеогенез в физиологических условиях сопровождается интенсивным образованием неорганической фазы при соотношении н-ГА/к-ГА, стремящимся к норме.

При туберкулезном остите титановые имплантаты подвергаются щелочной коррозии с локальным осаждением гидроксиапатита, что является ключевым фактором, запускающим репаративный остеогенез.

\section{Финансирование работы}

Работа выполнена при поддержке программы ГПНИ „Химические технологии и материалы“ (задание 1.04).

\section{Список литературы}

[1] Gaidash A.A., Sinitsa L.N., Babenko O.A., Lugovskoy A.A. // J. Osteoporosis. 2011. Vol. 2011. Article ID 162041. 7 p. DOI: $10.4061 / 2011 / 162041$

[2] Seung Min Jung, KyoungWoon Kim, Chul-Woo Yang, SungHwan Park, Ji Hyeon Ju // J. Immunol. Res. 2014. Article ID 263625. 15 p. http://dx.doi.org/10.1155/2014/263625

[3] Агапова О.И. // СТМ. 2017. Т. 9. № 2. С. 190-206. https://doi.org/10.17691/stm2017.9.2.24 [Agapova O.I. // CTM. 2017. Vol. 9. N 2. P. 190-206.]

[4] Крутько В.К., Кулак А.И., Мусскал О.Н. // Неорганические материалы. 2017. Т. 53. № 4. С. 427-434. DOI: 10.7868/S0002337X17040091 [Krut'ko V.K., Kulak A.I., Musskaya O.N. // Inorganic Materials. 2017. Vol. 53. N 4. P. 429-436.]

[5] Мусская О.Н., Кулак А.И., Крутько В.К., Лесникович Ю.А., Казбанов В.В., Житкова Н.С. // Неорганические материалы. 2018. Т. 54. № 2. С. 130-137.

DOI: $10.7868 / \mathrm{S} 0002337 \mathrm{X} 18020033$

[Musskaya O.N., Kulak A.I., Krut'ko V.K., Lesnikovich Yu.A., Kazbanov V.V., Zhitkova N.S. // Inorganic Materials. 2018. Vol. 54. N 2. P. 117-124.]

[6] Sargeant T.D., Guler M.O., Oppenheimer S.M., Mata A., Satcher R.L., Dunand D.C., Stupp S.I. // Biomaterials. 2008. Vol. 29. N 2. P. 161-171. https://doi.org/10.1016/j.biomaterials.2007.09.012

[7] Yanovska A.A., Stanislavov A.S., Sukhodub L.B., Kuznetsov V.N., Illiashenko V.Yu., Danilchenko S.N., Sukhodub L.F. // Mater. Sci. Eng. C. 2014. Vol. 36. P. 215-220. https://doi.org/10.1016/j.msec.2013.12.011

[8] Barrerea F., Snelc M.M.E., Van Blitterswijka C.A., De Groota K., Layrollea P. // Biomaterials. 2004. Vol. 25. P. 2901-2910. DOI: 10.1016/j.biomaterials.2003.09.063

[9] Shizuko Ichinose, Takeshi Muneta, Ichiro Sekiya, Soichiro Itoh, Hideki Aoki, Motoki Tagami // J. Mater. Sci. Mater. Med. 2003. Vol. 14. N 1. P. 79-86. https://doi.org/10.1023/A:1021557605458

[10] Boskey A.L., Donnelly E., Boskey E., Spevak L., Yan Ma, Wei Zhang, Joan Lappe, Recker R.R. // JBMR. 2016. Vol. 31. N 5. P. $1070-1081$. https://doi.org/10.1002/jbmr.2759

[11] Лемешева С.А., Голованова О.А., Туренков С.В. // Химия в интересах устойчивого развития. 2009. № 17. С. 327-332.

[12] Лемешева С.А., Голованова О.А., Муромцев И.В., Туренков С.В. // Вестник Омского ун-та. 2010. № 2. С. 106-112.

\section{Конфликт интересов}

Авторы заявляют, что у них нет конфликта интересов. 